\title{
Fostering biotechnology on the productivity and development of agricultural SMEs (Zimbabwe)
}

Ngoni Munyawarara

School of Management, IT and Governance, University of KwaZulu-Natal ngonimunyawarara70@gmail.com

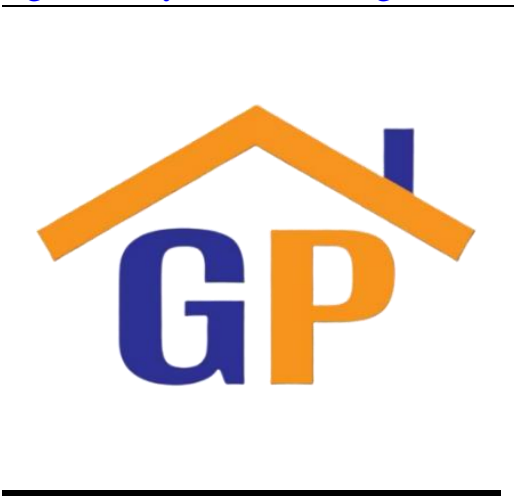

Article History

Received on 2 March 2020

$1^{\text {st }}$ Revision on 12 March 2020

$2^{\text {nd }}$ Revision on 29 April 2020

Accepted on 15 May 2020

\begin{abstract}
Purpose: This study scrutinizes the application of biotechnology in fostering the productivity of agricultural SMEs in Zimbabwe over the period 2019-2020. Fostering biotechnology around the world is significantly attracting much attention from agricultural entrepreneurs who have been lacking business productivity initiatives. As much this study attempts to unravel whether biotechnology is the spring bed for stimulating the productivity of agricultural SMEs to attain food security and nutriment.
\end{abstract}

Research methodology: A survey was used to get biotechnology data from archives of the National Biotechnology Association of Zimbabwe, concerning the use of biotechnology research in seeking to improve productivity by agricultural SMEs.

Results: The study showed that fostering biotechnology has demonstrable benefits that help SMEs to grow and increase food nutriment. The study recommended that investing in biotechnology has returns which are most apparent for SMEs to increase productivity and competitiveness in Zimbabwe

Limitation: The lack of a single study is a complex nature in the study and seemingly different instruments could produce a detailed analysis.

Contribution: The study encourages fostering biotechnology to improve the productivity and development of agricultural SMEs in Zimbabwe to attain food security and nutriment and poverty reduction.

Keywords: Biotechnology, Agriculture, SMEs, Development, Productivity, Food security

How to cite: Munyawarara, N. (2019). Fostering biotechnology on the productivity and development of agricultural SMEs (Zimbabwe). Journal of Sustainable Tourism and Entrepreneurship, 1(1), 13-22.

\section{Introduction}

Fostering biotechnology in SMEs in agriculture has not been widely exhausted using a wide range of strategies is available and has recently increased, leading to the growth of SMEs, especially by those in the agricultural sector (Brookes, and Barfoot, 2010). The growth and productivity of agricultural SMEs improves livelihoods by means of reducing hunger and poverty. The authors further state that biotechnological initiatives such as in vitro cell and embryogenesis among other forms are extensively used for the conservation of agricultural SMEs. Therefore, biotechnology is a powerful tool seeking to increase yields of modified conventional crops and micro propagated plants which establish more quickly, grow more vigorously and taller, and have a shorter and more uniformed productivity cycle to nip hunger (Bass, 2012; Sukume, Mavedzenge, Murimbarima \& Scoones, 2015; OECD, 2016). 
The facilitation of biotechnological capabilities maximise the productivity of SMEs in the agricultural sector through a combination of functional interactions to improve SME productivity and to allow them to reap huge profits and drastically grow into multinational companies (Bass, 2012; Yeboah, 2015). Fostering biotechnology increases crop productivity by introducing disease resistance and drought-tolerant crops (Brookes, and Barfoot, 2010; Tadele, 2017). Despite these scientific research advances in agricultural productivity, food insecurity, and poverty continue to be haunting many families. Thus there is a need for continued focus on fostering biotechnology to optimize agricultural output and preserving natural resources (Kertiyasa, Sukaatmadja, Jawas, Budhi, \& Marhaeni, 2013).

Therefore the purpose of this study is to examine the impact of fostering biotechnology in productivity and development of agricultural SMEs, particularly in the context of deepening agricultural uncertainty in Zimbabwe (Cloete, 2013).The increase in the application of biotechnology is becoming a powerful research tool that is playing a major role in agricultural SME development (Cloete, 2013; Yeboah, 2015; Wong, 2015). Many developing countries are fostering biotechnology to assist small farmers in increasing nutriment and generate jobs (Bass, 2012; OECD, 2016). However, concerns about Zimbabwe's persistently weak and nutriment have increasingly forced SMEs to use biotechnology to increase agricultural activities for them to irk a living (ZimVac, 2013; FAO, 2017). At the same time, a growing body of evidence has emerged to show that SMEs which engage in the more extensive use of biotechnology increase productivity (Antoniou, Robinson and Fagan, 2012; Bass, 2012; Wong, 2015).

The evidence is particularly strong for the agricultural SME sector, where recent studies in Cuba have shown rewarding results in the use of biotechnology (Brookes and Barfoot, 2010). Under this perspective, the lesser use of biotechnology among developing SMEs might be attributed to a lack of knowledge about its realizable benefits. An alternative perspective argues that SMEs have distinctive characteristics such as illegal underhand dealings which can make the use of biotechnology inappropriate. However, the ignorance use of biotechnology cannot then be expected to deliver benefits and may even be harmful to crops and the environment. The SMEs in agriculture is poorly producing food, thereby stifling their growth. Hence the study seeks to encourage smallholders farmers to foster biotechnology as a strategy to improve their productivity and growth (Brookes and Barfoot, 2010; Chingwaru \& Jarkata, 2015). Hence farming methods must be used such as fostering biotechnology to achieve and nutriment. Therefore the aim of this study is to evaluate the impact of fostering biotechnology on agricultural SMEs. This paper evaluates if there is a significant association between fostering biotechnology and the productivity and development of agricultural SMEs.

This study, therefore, makes the following hypothetical statements:

Ho1: fostering biotechnology has the significance associated with the productivity and development of agricultural SMEs.

\section{Literature review and hypotheses development}

\section{Fostering biotechnology}

The literature contributed by examining the impact of fostering biotechnology on developing agricultural SMEs in Zimbabwe over the period 2019-2020, using dataset and high-quality survey data from the Biotechnology Association of Zimbabwe (BAZ) archives. This dataset provides detailed information on fostering biotechnology, in this sector though it is likely to be largely used by larger companies. In recent years, there has been a growing interest in biotechnological research to increase and nutriment. The study is motivated in part by a substantial body of evidence which documents biotechnology as an effective tool to improve food nutriment. This literature has focused on the extent to which such heterogeneity maybe explained by observable differences in SMEs' use of biotechnology (Antoniou et al, 2012).

Biotechnology matters are far from new, the productivity of datasets that link information on fostering biotechnology has allowed this aspect of the subject to become scrutiny (Yeboah, 2015). One strand 
of fostering biotechnology in this vein has focused primarily on agricultural SMEs. Studies in this area have sought to investigate the contention that fostering biotechnology can aid food nutriment by:

- helping agricultural SMEs to radically develop

- structuring SME activities in such a way to ensure and nutriment is improved and

- encouraging SMEs to globally compete with multinationals

As such biotechnology is the 'Mother of Invention' and agricultural SME productivity is dependent on scientific research to produce quality yields and increase food autonomy (Tadele, 2017).

As such, the idea of biotechnology is traced back to Schumpeter (1934) who associates business with new things where the old systems are discarded. Henceforth, the spotlight on encouraging the use of biotechnology manipulates the DNA to change the hereditary SME traits to produce high-quality agricultural SME products as a necessary intervention of food insecurity measures (Tadele, 2017). All this contributes to poverty reduction and widely addresses food insecurity and nutriment concerns.

As such Zimbabwe has chronic food insecurity and nutriment and malnutrition due to lack of biotechnology research and productivity (Bass, 2012; Yeboah, 2015). This stunt remains a major challenge in Zimbabwe where less the majority consume the minimally acceptable diet. Despite these mitigating circumstances, modern biotechnology represents the unique fostering of science that can be used for the betterment of agricultural activities through supporting SME scientific research initiatives. The effect of biotechnology fostering is associated with higher food security and nutriment. Food and Nutrition Council of Zimbabwe (2012) undertook a similar study of agricultural SMEs. The evidence from this strand of work on fostering of biotechnology among developing agricultural SMEs has thus been somewhat equivocal. However, evidence suggests that SMEs find it more difficult than larger SMEs to identify and adapt to innovative technologies and working methods due to their weaker internal resources. This fostering of biotechnology has demonstrable benefits, on average, for SMEs that use it. The extensive use of biotechnology helps SMEs to grow and increase and nutriment. The returns of using biotechnology are most apparent in agricultural productivity.

Therefore this study seeks to investigate the fostering of biotechnology among developing agricultural SMEs in Zimbabwe, a high-tech sector case study in Urban Mutare.Therefore the hypothesis was that there is a positive relationship between fostering biotechnology and developing agricultural SMEs in seeking to increase and nutriment in Zimbabwe (Antoniou et al ,2012; ZimVac, 2013). This study provides much insight into the issue, to develop the hypothesis. As such, this study contributes to an understanding of the information about fostering biotechnology in agricultural SMEs in Zimbabwe

\section{The agricultural sector implication}

The role played by fostering biotechnology on instances has become the key priority sector for food provision and poverty reduction (Kertiyasaet al, 2013). The focus of every government is to provide and nutriment for its citizens even way before industrial growth is considered as a means to advance nutriment. Even though the agricultural sector faces aggressive competition from various elements of globalization, it remains a positive influence on hunger and poverty reduction in Central, Eastern and South-Eastern Asia and Latin America through the promotion of the growth of SMEs which then improve and nutriment (FAO, 2014; UNDP, 2012). In this case, India has increased its food production by nearly 112 percent in early 2000 from 50 percent in 1988 and the Cuban agricultural revolution has optimized intensive and meticulous agriculture to double and nutriment and their agricultural SMEs have become more efficient (Ministry of Agriculture, Mechanization, 2014; FAO, 2017).

Most African governments have not prioritized SMEs in the agriculture sector, especially in rural and farm community areas, despite their notable contributions to their countries' GDP. From this perspective, Bindu \& Chigusiwa, (2013) claims the disconnection on the growth of SMEs is partly due to the complexity of the poor fostering of biotechnology in the agricultural landscape. The progress of agricultural SMEs has been slow particularly in Zimbabwe since the country's disruptive and rhetoric policies have often frustrated efforts to improve the agricultural sector (ZimVac, 2013; 
Nyamutowa, Masunda\&Mupaso, 2014). The motives may be numerous and wide-ranging, but what is understandable is the need to adopt sound policies for agriculture development (Cloete, 2013).Furthermore Zimvac (2013) agrees that farming has a central responsibility to have to build a strong Zimbabwean economy.

Thus, the value of agriculture is unlocked through strategies for fostering biotechnology the growth of SMEs in the agricultural sector. Explicitly, this indicates that through fostering biotechnology on SMEs, it is expected that their activities would become commercial and provide a linchpin for increased productivity (Bass, 2012). It is against this backdrop that the growth of agricultural SMEs' is achieved via a mix of fostering biotechnology strategies.

\section{Agricultural SMEs}

The agricultural SME sector is heterogeneous and approximately many indigenous people operate agricultural SMEs in developing countries (Bass, 2012). The SMEs are split into small and medium enterprises by size and are both formal and non-formal (Bindu \& Chigusiwa, 2013). They generate jobs and food in communities. A large percentage of them are small and practice mixed farming. According to the Food and Nutrition Council of Zimbabwe (2012) and ACET (2015) the agricultural SMEs are essentially owned by reluctant farmers who do not have much experience. By definition, the small enterprises comprise 3- 30 employees and medium enterprises comprise entities with 31-100 employees. However, the poor agricultural activities of SMEs have been viewed by Finmark Trust (2012) as entities that need to refocus and be revolutionized through a fostering biotechnology process to improve farming processes and outputs. Rigorous research on the best mechanisms which can be applied to re-engineer agricultural SMEs in developing countries is very limited, leaving SMEs with little guidance on which programs to apply in engineering their growth and sustainability (ACET, $\underline{2015}$.

From this discussion, there are increased chances for SMEs in the sector to be reorganized and for them to focus on strategies to fostering biotechnology themselves to satisfy food provisions needs (Anseeuw, Kapuya, \& Saruchera, 2012). SMEs in the agricultural sector lack shared approaches that are in line with global standards, as evidenced by the absence of strategic management approaches. This is what leads to poverty and increased food insecurity. Unlike in developed countries, SMEs in the agricultural sector in most African nations do not take a business approach to their activities and this affects their outputs (AfDB, 2013). Furthermore, there are limitations embedded in government policies which often become impediments to agricultural SMEs, when they should be the major employer in Zimbabwe (Zimvac, 2013). From the above discussion, it is apparent that the achievement of turning around the Zimbabwean agricultural SMEs depends on fostering biotechnology SMEs, through diverse government policies and strategies.

\section{Development}

The UN FAO (2017) defines and nutriment as having safe, adequate, and nutritious rations. However, the essence of this study concerns key variables to attain and nutriment and economic growth through strategies for fostering biotechnology agricultural SMEs since the food consumption rate is rising each day (ACET, 2015). Besides, the agricultural sector plays a strategic function in the increase of food production and per-capita income rise. To this end, the 21 stcentury has been increasingly focusing on strategies for fostering biotechnology SMEs in the agricultural sector to improve and nutriment. The OECD (2016) describes and nutriment as the state where people have surplus food to sustain themselves since shortages of food causes famine and malnutrition. The essence of the study is to reengineer agricultural SMEs to promote productivity and to avert the dangers of starvation (Bass, 2012; World Food Summit, 2017).

In line with this general relief, the government introduced support programs to restore macroeconomic stability and productivity in all food and agricultural SMEs initiatives (Bass, 2012; ZimVac, 2013). This approach to and nutriment is the constitutional rights of citizens who have access to adequate food. It is in this context that comprehensive agricultural support programs are needed which 
ensure the development and competitiveness of SMEs and aid in agricultural transformation (Ministry of Agriculture, Mechanization, 2014; Cloete, 2013). The locus of food security and nutriment takes stock of progress made towards achieving the internationally established hunger and poverty reduction targets (Kertiyasaet al, 2013). Hence, the food insecurity eradication and growth of agricultural SMEs should remain a key commitment of decision-makers at all levels.

Historically, agricultural productivity is measured by Total Factor Productivity (TFP) which reflects in the efficiency of combining the SMEs' inputs to produce (outputs) (FAO, 2014). It is in line with this that the improved agricultural output contributes substantially to the overall economic development hence the justification to place a bigger emphasis on fostering biotechnology agricultural SMEs. According to Food and Nutrition Council (2012), most of Zimbabwe's increased the food output is no longer a result of the expansion of an area used in agriculture but comes from strategies for fostering biotechnology agricultural SMEs to intensify the growth and productivity of SMEs in the agricultural sector (Anseeuwet al , 2012).

As such, the Washington-based International Food Policy Research Institute believes that research in agriculture increases the ability to feed the growing population (Ministry of Agriculture, Mechanization, 2014). Although a large proportion of SADC's poor communities are engaged in agriculture, governments spend large amounts of their budget to fulfill the demand for food. Zimbabwe is, therefore, supporting agricultural SMEs to eliminate inequalities and poverty amongst its households (AFDB, 2013). The agricultural SME sector's food productivity is growth-orientated and focuses more on the center of strategic thrusts to improve food safety and nutriment. This is supported by the agricultural sector across the globe to ensure food safety and nutriments are attained through growing SMEs. The new SME entrants into farming with innovative ideas, however, they lack government support on how to increase sustainable growth (Wong, 2015).

Therefore, the rationale behind fostering biotechnology SMEs in the agricultural sector is to have adequate food as a strategy to eliminate threats of undernourishment and hunger.

\section{Research methodology}

The descriptive design was appropriate for this study as it helped to describe the state of affairs as they existed without manipulation of variables (Kumar, 2014). The target population of this study consisted of the SMEs in Urban Mutare. The main reason for choosing agricultural SMEs was because they exist in a high tech agricultural area. The study targeted SMEs registered with the Biotechnology Association of Zimbabwe.

A sample of 60 respondents was approached to collect data using questionnaires (Creswell, 2013; Saunders, Lewis, \& Thornhill, 2013). The reason for choosing a questionnaire as the data collection instrument was primarily due to its practicability, applicability to the problem and the size of the population and it's cost-effective. In analyzing the quantitative data, the study used descriptive Statistical Package for Social Sciences (SPSS) which was appropriate to present the data findings (Etikan \& Bala, 2017).

\section{Results and discussions}

The objective of the study sought to establish the impact of biotechnology fostering and nutriment among developing agricultural SMEs in Urban Mutare, Zimbabwe (ZimVac, 2013). The findings are as discussed as follows;

\section{Respondent Biotechnology educational background}

The respondents' background showed that $30 \%$ of SME owners have degrees in biotechnology. The rest $70 \%$ were none qualified though they hold other qualifications in agriculture. This indicates that more education is needed on biotechnology courses that seek to develop the agricultural sector and SME growth. 


\section{Figure 1: The extent of biotechnology knowledge on SME activities}

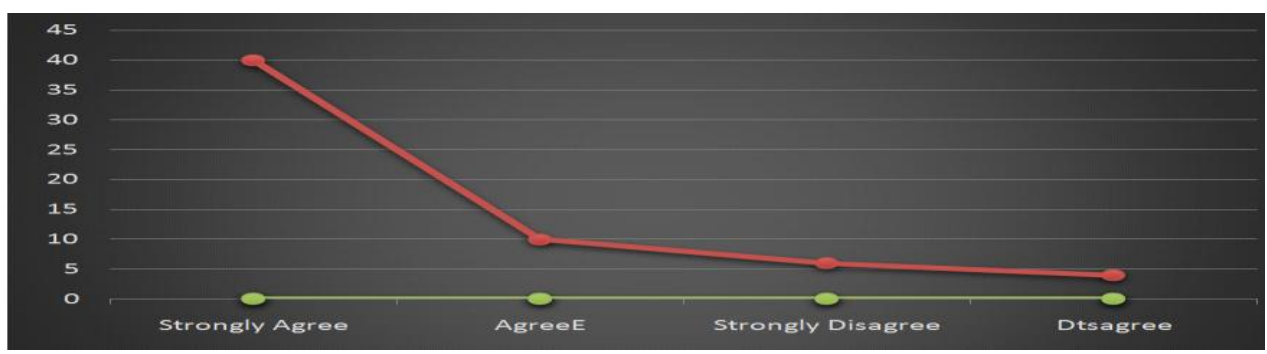

The study sought to find out whether the respondents had a clear understanding of biotechnology and its importance to stimulate their productivity (Bass, 2012). The findings are as shown in Figure 1. Respondents' knowledge of biotechnology shows (66.666\%) of the respondents indicated that they had a clear understanding of biotechnology while $8.333 \%$ indicated that they lacked a clear understanding of biotechnology.

This showed that the majority of the respondents had a clear understanding of biotechnology and as such appreciated the influence of biotechnology on food security and nutriment. These findings are in line with Tadele (2017) who noted that fostering biotechnology is a unifying theme that gives coherence to SME food safety and nutriment? On his part, Brookes and Barfoot (2010) argued that in agriculture, SMEs must use biotechnology to increase productivity and grow into formidable entities.

\section{Figure 2: Extent to which biotechnology can develop agriculture and SMEs}

The findings are as illustrated in figure 2 below

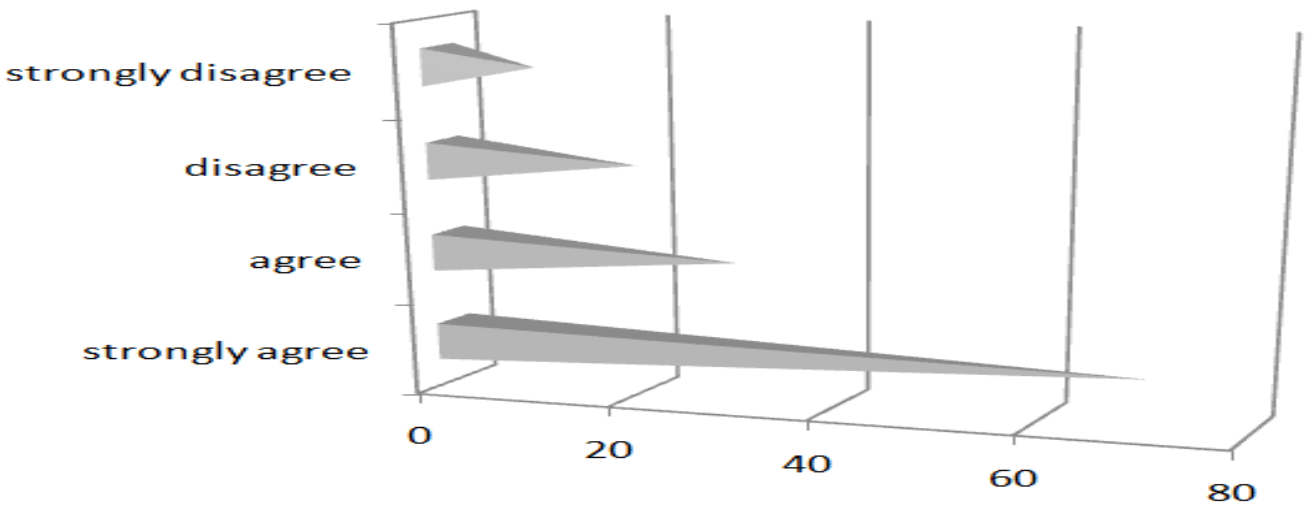

Figure 2 shows the extent to which biotechnology fostering was used shows that over $60 \%$ of the respondents indicated that SMEs are using biotechnology to increase food production while 5.344\% of the respondents indicated that their activities are not dependant on scientific research. The study also concluded that SMEs could ensure effective biotechnology research implementation through government support (Brookes and Barfoot, 2010). The study further concluded that the adoption of biotechnology research helped agricultural SMEs to improve on their performance in various ways such as productivity in the customer base, the productivity of new products and services (OECD, 2016). 
Figure 3: Extent to which biotechnology fostering influence and nutriment

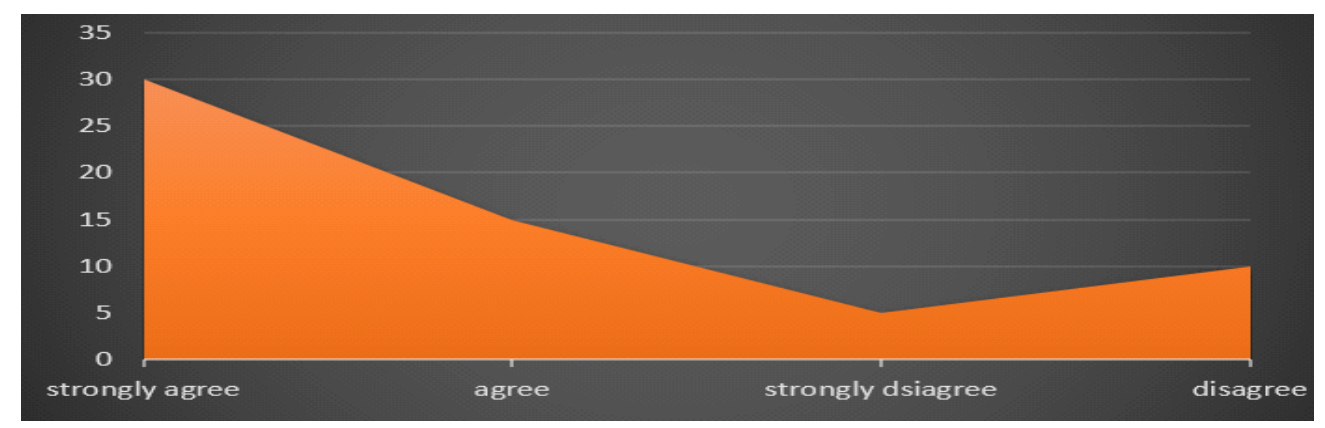

The study sought to find out whether the respondents had the clear understanding of how biotechnology can influence food security and nutriment ZimVac (2013). The findings are as shown in Figure 3. The Respondents' knowledge on the extent to which biotechnology fostering influence and nutriment and nutriment show that the majority of the respondents indicated that they had a clear understanding of the impact of biotechnology on food nutriment and safety while $10 \%$ indicated that they lacked a clear understanding of the effect of biotechnology.

This showed that the majority of the respondents had a clear understanding of the effect of scientific research of biotechnology and as such appreciated its influence on reducing poverty, diseases, and hunger (Kertiyasaet al, 2013). These findings are in line with Tadele (2017) who noted that biotechnology fostering is a unifying theme that gives coherence to the productivity of food reserves. On his part, Brookes and Barfoot (2010) argued that in agriculture, SMEs must use biotechnology to increase productivity and grow themselves into formidable entities.

\section{Hypothesis Dimension}

Fostering biotechnology contributes positively to the performance of SMEs and therefore, the hypothesis $\mathrm{H} 1$ : fostering biotechnology has a significance associated with productivity and development of agricultural SMEs.The results indicate that fostering biotechnology on SMEs significant increases in their productivity and development (p-value of 0.000 ) less than $(\mathrm{p}<0.05)$ 0.0005.This indicate that the result is significant, thereby supporting the hypothesis. Biotechnology has been able to transform SME growth and increase in their performance. The findings as supported by FAO (2017) which stated that productivity in the agricultural sector is buttressed by biotechnology. Hence, various SMEs were using biotechnology to attain development (ACET, 2015). These results are consistent with the findings of OECD (2016) and Brookes and Barfoot (2010) which indicated that SMEs are able to use various biotechnology research tools, to improve their productivity and development goals.

\section{Conclusion}

The study concluded that the adoption of biotechnology enabled SMEs to match their output with the market demand, to have a clear purpose and direction, align their objectives and nutrient targets. The study also concluded that the SMEs could ensure effectively biotechnology strategy influence and nutriment strikes a balance and improve organizational productivity. The study further concluded that the adoption of fostering biotechnology improves SME performance in various ways such as productivity in the customer base, the productivity of new products and services, achievement of better coordination of organizational activities, productivity in the firm revenues, the opening of new branches, stability, and effective management.

SMEs like any other organizations operate in a competitive and dynamic environment and hence fostering biotechnology is a tactic for survival. The volatile nature of current markets makes 
biotechnology a critical management tool. The study thus recommends that the Government of Zimbabwe and key stakeholders come up with a mechanism/legislation that will streamline the fostering biotechnology in the every sector, but also put up mechanisms for having such biotechnology policies fully implemented. On their part, SMEs need to consciously engage in a systematic environmental scanning, develop effectively mission statements, objectives and commit themselves unto fostering biotechnology implementation, evaluation, and control. This is despite the study showing that the SMEs that biotechnology practices, the flow, and coordination of the entire biotechnology strategic management process has not been practiced yet. The study encourages future researchers to study fostering biotechnology on SMEs at a large scale to improve the productivity and development of the agricultural sector as a measure to increase food security and nutriment.

\section{Limitation and study forward}

Since this study explored the influence of biotechnology in Harare similar studies should be done on other sectors in Zimbabwe for comparison purposes and to allow for generalization of findings. In addition, given the complex nature of biotechnology, no single study can test it in its entirety; hence future studies should identify more variables associated with fostering biotechnology on SMEs' productivity. This study did not use different instruments to produce a detailed analysis; hence the narrow range of data structures a risk to the integrity of the study. In line with the current study, future research is required in the area of fostering biotechnology support approaches on all SMEs in order to understand the advantages of fostering biotechnology to help them adapt to changes and enable their development.

\section{Acknowledgment}

The authors appreciate support from Biotechnology Association of Zimbabwe (BAZ) and the Ministries of SMEs and Agriculture in Zimbabwe.

\section{References}

Antoniou, M., Robinson, C., and J. Fagan. (2012) .GMO myths and truths: An evidence-based examination of the claims made for the safety and efficacy of genetically modified crops. Earthopensource,London. http://www.akleg.gov/basis/get documents.

Anseeuw, W., Kapuya, T. \&Saruchera, D. (2012). Zimbabwe's agricultural reconstruction: Present state, ongoing projects and prospects for reinvestment. Productivity Bank of Africa, Productivity Planning Division, Working Paper Series No. 32, South Africa.https://www.researchgate.net/publication/273143750

ACET. (2015). Promoting sustainable rural development and transformation in Africa - Synthesis report lessons learned across 5 countries: Accra. African Center for Economic Transformation Cantonments.

AFDB. (2013). Agricultural Value Chain Financing (AVCF) and development for enhanced export competitiveness. African Development Bank Paper. Ghana. https://www.afdb.org/fileadmin/uploads

Bindu .S., Chigusiwa, L. (2013). Examining the sources of SMEs horticultural farmers, exclusion from formal urban markets in Zimbabwe: The case of Chihota communal areas. Journal Development Agriculture Economics, 4(6), 1-12. http://www.ijeronline.com/documents

Bass, H. (2012). SMEs Productivity in the 21st Century. New York: Routledge. Retrieved 13.01.2020.

Cloete, P.C. (2013). Institutions and Agricultural Development: the Case of the North West Province in South Africa. Africa Journal of Agriculture Res, 8(27), 3495-3504. https://pdfs.semanticscholar.org.

Chingwaru, T., \&Jarkata, O. (2015). Factors restraining Small to Medium Enterprises (SMEs) from engaging in export market: The Case of the Manufacturing Sector in Harare, Zimbabwe. International Journal of Science and Research, 2, 643-647. https://www.ijsr.net/archive/v4i10/SUB158737.pdf. Retrieved 05.02.2020

Creswell, J. W. (2013). Qualitative inquiry and research design: Choosing among five approaches, $3^{\text {rd }}$. ed. Singapore: Sage Publications Inc. Retrieved 31.12.2019. 
Etikan, I., \& Bala, K. (2017). Combinations of probability random sampling method with non probability random sampling method (sampling versus sampling methods). BiomBiostat Int. Journal, 5(6), 1-5. https://medcraveonline.com

Finmark Trust. (2012). Finscope MSME survey, Zimbabwe. http://www.finmark.org.za.

FAO. (2014). The state of food and agriculture innovation in family farming. Rome: United Nations.

Food and Nutrition Council of Zimbabwe, (2012). Policy - food and nutrition security for Zimbabwe in the context of Economic Growth and development. https://extranet.who.int/nutrition/gina/en/node/14829

Brookes, G., \& P. Barfoot, P. (2010). Global impact of biotechnology crops: Environmental effects, 1996-2008. AgBioForum, Vol. 13 Issue, pp 76-94, http://www.agbioforum.org.

FAO. (2017). The future of food and agriculture, trends and challenges. Rome: United Nations.

Kertiyasa, N. N., Sukaatmadja, P. G. Jawas, A.,Budhi, M. K.S., \&Marhaeni, A.A. I. (2013). SME performance improvement and its effect on the poverty reduction in Bali. International Journal of Business and Management Invention, 2(4), 1-12. http://www.ijbmi.org/papers

Kumar, R. (2014). Research methodology: A step by step guide for beginners. $3^{\text {rd }}$ Edition, Singapore: SAGE Publications.

Ministry of Agriculture, mechanization and irrigation (2014). Development. Second round crop and livestock assessment report. https://documents.wfp.org.

Nyamutowa, C., Masunda S., \& Mupaso, N. (2014). Assessing the readiness of Zimbabwe in Adoption of an agricultural commodity and derivatives market. A review paper. Midlands State University Journal of Science, Agriculture and Technology, 5(1), 95-110. Retrieved 03.01.2020

OECD. (2016). Sustainable productivity productivity in agriculture: Trends and policy performance. Better policies for better lives. Meeting of Agriculture Ministers, 7-8 April, Paris. www.oced.org/agricultural/ministerial.

Sukume, C., B., Mavedzenge, F. Murimbarima, \& Scoones, I. (2015). Space, markets and employment in agricultural productivity: Zimbabwe Country Report. Research Report 46. Cape Town: University of the Western Cape, Institute for Policy, Land and Agriulture Studies (PLAAS). https://assets.publishing.service.gov.uk

Saunders, M., Lewis, P., and Thornhill, A. (2012). Research methods for business students. 7th Ed. Harlow: Prentice Hall.

Schumpeter J. (1934). Theory of economic development: An inquiry into profits, capital, credit, interest, and the business cycle. Cambridge, MA: Harvard University Press.

Tadele, Z. (2017). Raising crop productivity in Africa through intensification institute of plant sciences, Switzerland Center for Productivity and Environment (CDE), Switzerland. https://www.mdpi.com/2073-4395

UNDP. (2012). Africa human development report: Towards a food secure future. New York: United Nations Development Programme Regional Bureau for Africa (RBA). https://www.undp.org/content/dam.

World Food Summit. (2017). Better food for more people conference. Copenhagen, Denmark :Ministry of Environment and Food. https://bfmp.dk

Wong, G. (2015). SMEs productivity, measurement and analysis, handbook, Japan Tokyo:Asian Productivity Organization.

Yeboah, M.A. (2015). Determinants of SME Growth: An empirical perspective of SMEs in the cape coast metropolis, Ghana, Journal of Business in Developing Nations, 14(1), 2-31. Retrieved $\underline{13.01 . .20}$

ZimVac.(2013). Rural livelihoods assessment draft report. Harare, Zimbabwe. https://reliefweb.int/sites. 


\section{Appendix A; Questionnaire for agricultural SMEs}

Information:

\section{Declaration by Respondent}

I hereby consent to voluntarily take part in the completion of this questionnaire.

Participant Signature

Answer all questions; please consign an (X)/tick where appropriate.

\section{Section A: Respondent Biotechnology Educational Background}

1. Tick by indicating an $\mathrm{X}$ to show your highest biotechnology qualification?

Non-Qualified

Certificate

Diploma

Degree

\section{Section B Agricultural r SMEs}

Now answer the following questions using a scale of 1- 4 where $4=$ Strongly Agree; 3 Agree; $2=$ Strongly Disagree; $1=$ Disagree.

2.

\begin{tabular}{|l|l|l|l|l|}
\hline $\begin{array}{l}\text { From your own knowledge and understanding of fostering } \\
\text { biotechnology, does it stimulate agricultural SME productivity? }\end{array}$ & 1 & 2 & 3 & 4 \\
\hline
\end{tabular}

3.

\begin{tabular}{|l|l|l|l|l|}
\hline $\begin{array}{l}\text { To what extent do you think fostering biotechnology influence } \\
\text { agriculture and SME development in Zimbabwe? }\end{array}$ & 1 & 2 & 3 & 4 \\
\hline & & & & \\
\hline
\end{tabular}

4.

In your opinion to what extend does fostering biotechnology on agricultural SMEs influence and nutriment?

\begin{tabular}{|l|l|l|l|}
\hline 1 & 2 & 3 & 4 \\
\hline & & & \\
\hline
\end{tabular}

\section{End of Survey}

